
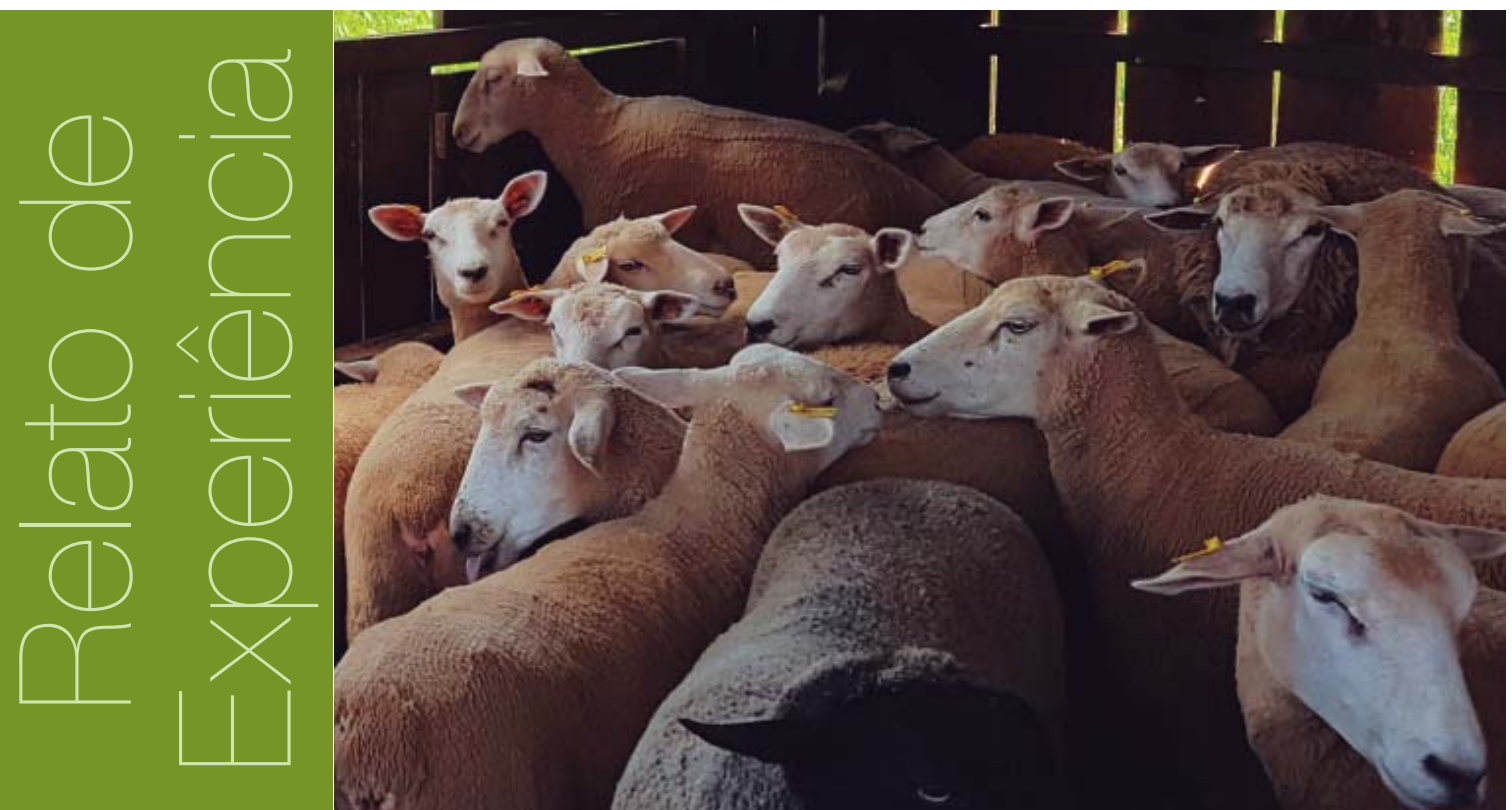

\title{
Estímulo em processos produtivos da ovinocultura nos municípios de abrangência do IFRS - Câmpus Sertão
}

Bruno Dos Santos Da Silveira1 - cttbrunosantos@gmail.com Melânia Lazzari Rigo² - melania.rigo@bento.ifrs.edu.br Ângelo O. C. Tamiozzo' - angelootaviotamiozzo@gmail.com

Ricardo Durante1 - ricardo_09d@hotmail.com

\section{RESUMO}

Com 0 intuito de disseminar conhecimentos e solidificar a produção de ovinos na região, acadêmicos e docentes do curso de zootecnia do IFRS - Câmpus Sertão elaboraram um projeto de extensão voltado a unidades de produção agropecuária presentes no entorno do Câmpus. Através de metodologias básicas e técnicas acessíveis, realizaram-se eventos e visitas a propriedades, oportunizando a troca de experiências que contribuem para uma constante evolução da ovinocultura e formação de profissionais qualificados.

\section{PALAVRAS-CHAVE}

Ovinocultura. Desenvolvimento. Zootecnia. Extensão.

\section{ABSTRACT}

Aiming to disseminate knowledge and solidifying the production of sheep farming in the region, academics students of the zootechnical course and teaching staff of IFRS - Campus Sertão develop an extension project related to agricultural production units that are presented around the Campus. Through basic methodologies and accessible techniques, events has

1 Acadêmicas do Bacharelado em Zootecnia do IFRS - Campus Sertão

2 Médica Veterinária, Professora do IFRS - Campus Bento Gonçalves 
been taking place, as well as visits to properties, promoting the opportunity for exchanging experiences, corroborating the constant evolution of sheep farming and the training for qualified professionals.

\section{KEYWORDS}

Sheep farming. Development. Zootechnics. Extension.

\section{Relato de experiência}

A produção de ovinos é uma das atividades pecuárias fundamentais no Rio Grande do Sul (CELESTINO, 2009, 1187-1192). Sua importância econômica e social está relacionada principalmente à possibilidade de utilização de áreas inadequadas para a agricultura, além da produção em sistemas de integração lavoura-pecuária-floresta, permitindo a maximização dos espaços existentes nas unidades de produção agropecuárias (UPAs), proporcionando diversificação produtiva, além de auxiliar no acréscimo da renda final da propriedade.

Atualmente, a ovinocultura está estimulada principalmente pela procura da carne de cordeiro, havendo a oportunidade de técnicos incentivarem esta produção. Nos municípios de abrangência do Instituto Federal de Educação, Ciência e Tecnologia do Rio Grande do Sul - Câmpus Sertão, a produção de ovinos ainda apresenta-se como uma atividade secundária, sendo o foco produtivo a produção de grãos e a bovinocultura leiteira. Nesse sentido, a ovinocultura enfrenta dificuldades de consolidação pelo desconhecimento dos produtores sobre 0 manejo e tecnologias de produção na área, além da falta de assistência técnica especializada e comprometimento por parte dos órgãos governamentais. Entretanto, apesar das carências observadas, os produtores de ovinos da região demonstram interesse pelo aperfeiçoamento profissional, tanto do ponto de vista técnico quanto gerencial, objetivando ofertar ao mercado consumidor um produto homogêneo, de qualidade e com estabilidade de oferta (TAMIOZZO, 2016, 68-71). Desta forma, faz-se necessário conhecer e incentivar a produção de ovinos no município de Sertão e entornos, estimulando este novo mercado, e consequentemente 0 desenvolvimento regional.

Com este propósito, acadêmicos e docentes do Instituto Federal de Educação, Ciência e Tecnologia do Rio Grande do Sul - Câmpus Sertão desenvolveram pelo segundo ano consecutivo o projeto de Extensão "Diagnóstico e Fomento da Ovinocultura em Propriedades nos Municípios de Abrangência do IFRS - Câmpus Sertão". 0 objetivo principal do projeto é promover a profissionalização dos ovinocultores, transferindo tecnologias acessíveis e de baixo custo, estimulando-os a visualizarem suas unidades de produção como empresas, gerenciando-as de forma hábil do ponto de vista técnico e econômico, além de produzir informações concretas e confiáveis a respeito da atividade ovina nesta região.

Dessa forma, o projeto iniciou com um contato e convite aos ovinocultores da região, para que voluntariamente participassem do trabalho. Após a aceitação, foi realizado um questionário com 0 intuito de desenvolver um diagnóstico da UPA, levando em conta aspectos sociais, econômicos e produtivos. Com base nessas informações, foram elaborados relatórios individuais para cada UPA, específicos a cada realidade encontrada, enaltecendo os pontos positivos e frisando os pontos de estrangulamento da produção de ovinos, onde através de visitas regulares às UPAs (Figura 1), eram apresentadas técnicas e práticas acessiveis que possibilitassem a correção e melhoria das carências encontradas. Dentre as atividades mais desenvolvidas nas propriedades foram técnicas de manejo sanitário, destacando-se 0 controle de verminoses através da técnica Famacha $₫$, bem como 0 casqueamento corretivo e preventivo para enfermidades podais, demostrando aos criadores como estas práticas devem ser abordadas, nos relatórios entregues aos mesmos. Ainda, de acordo com a alimentação disponível em cada propriedade, adequaram-se dietas para as diferentes categorias animais, e estas, entregues aos produtores, ressaltando a importância de uma dieta adequada para se obter um bom desenvolvimento dos animais, e também, a influência desta na reprodução e na saúde dos mesmos. Com relação aos aspectos reprodutivos, não deu-se tanta relevância, pois frente ao diagnóstico levantado, as propriedades assistidas não demostraram deficiência 
neste aspecto. Durante o segundo ano de desenvolvimento do projeto, a equipe conseguiu abranger periodicamente cinco UPAs, distribuídas entre os municípios de Sertão, Estação, Itatiba do Sul, Coxilha e Marau, atendendo as principais deficiências de cada uma, com maior ênfase nos aspectos sanitários conforme descrito.

Figura 1: Visitas técnicas aos ovinocultores participantes do projeto.

Fonte: Melânia Lazzari Rigo.

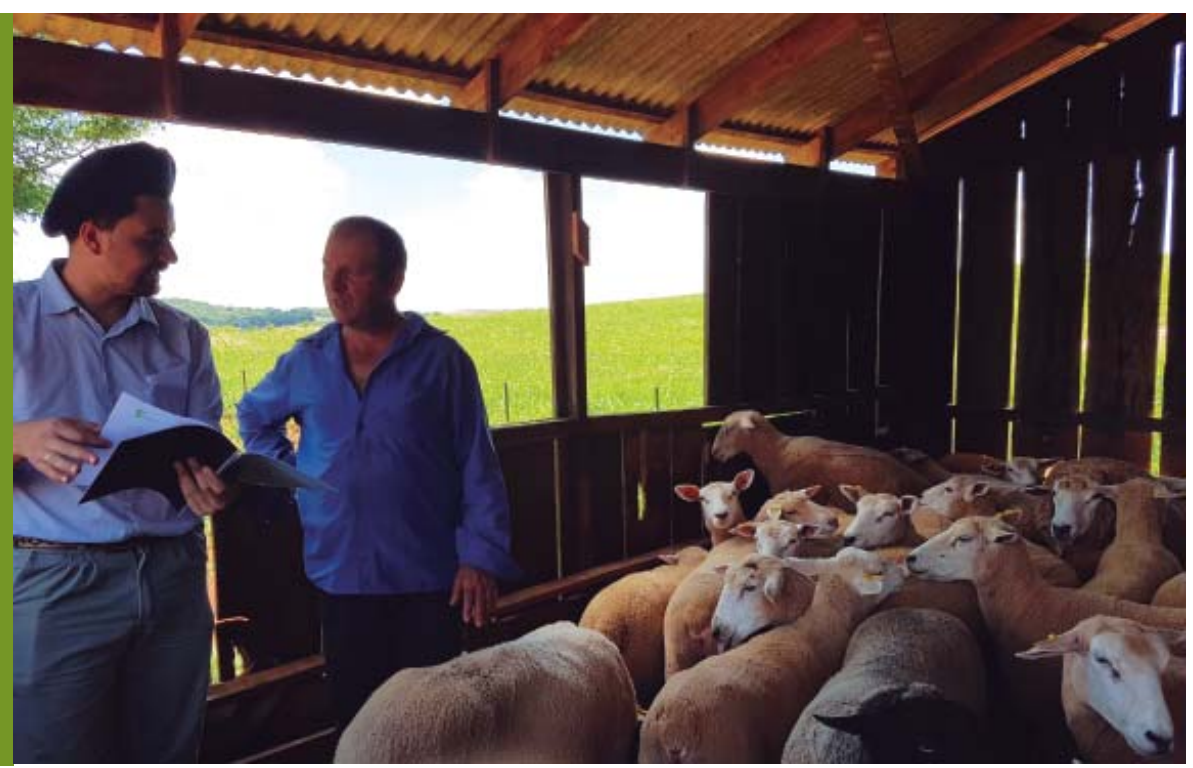

Além disso, por meio deste projeto, juntamente com a Emater/Ascar - Sertão/RS e o Grupo de Estudo e Pesquisa em Pequenos Ruminantes do IFRS - Câmpus Sertão (GEPRUM), foram promovidas ações de extensão que visaram não só compartilhar os conhecimentos desenvolvidos dentro da instituição de ensino, mas também, buscar o envolvimento da comunidade externa dentro da instituição, a fim de integrá-la e torná-la participativa na execução de discussões, e auxiliar no desenvolvimento regional. Para tal, desenvolveu-se, um curso de inseminação artificial cervical em ovinos (Figura 2), dois eventos com palestras e demonstrações práticas (Figura 3), sobre manejo no pré-parto e cuidados com os cordeiros recém nascidos, e duas mesas-redondas abordando experiências de estudiosos e produtores ligados à ovinocultura, com foco principal no controle de endoparasitas. Estes eventos obtiveram excelência em participação de alunos e ovinocultores da região, gerando não somente aprendizado, mas também contato e troca de experiências entre os participantes, fortalecendo a cadeia produtiva de ovinos como um todo. Com 0 intuito de compartilhar o projeto, bem como seus resultados e perspectivas, este foi apresentado no evento I SerTão Aplicado, realizado no IFRS - Câmpus Sertão e posteriormente, no I Salão de Pesquisa, Extensão e Ensino do IFRS com abrangência estadual, onde o mesmo recebeu a premiação de destaque na categoria extensão.

Figura 2: Prática realizada durante 0 curso de inseminação artificial cervical em ovinos.

Fonte: Guilherme Afonso Müller Rodrigues.

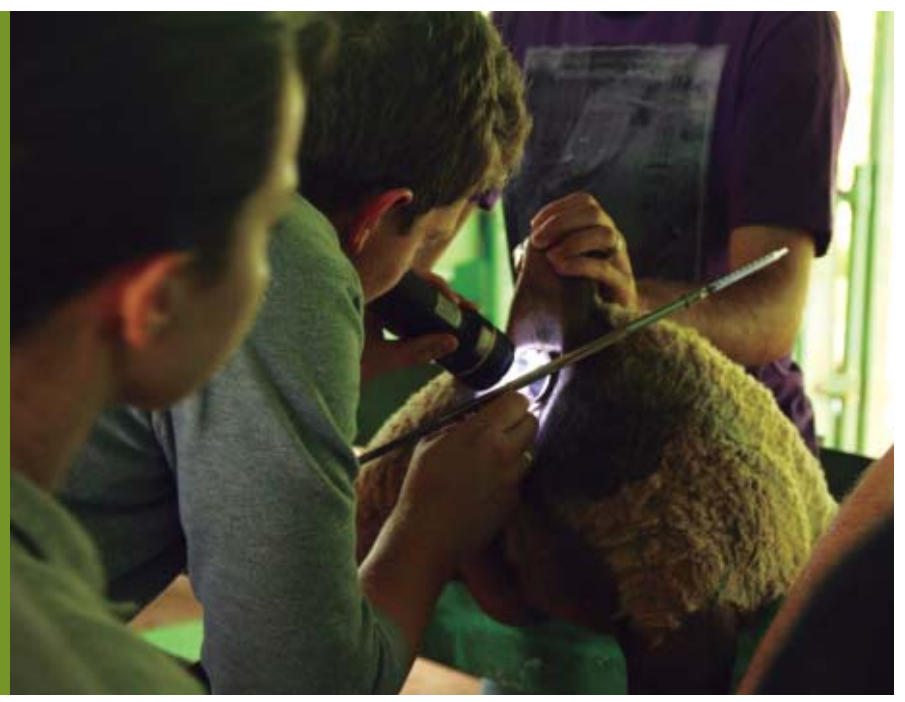




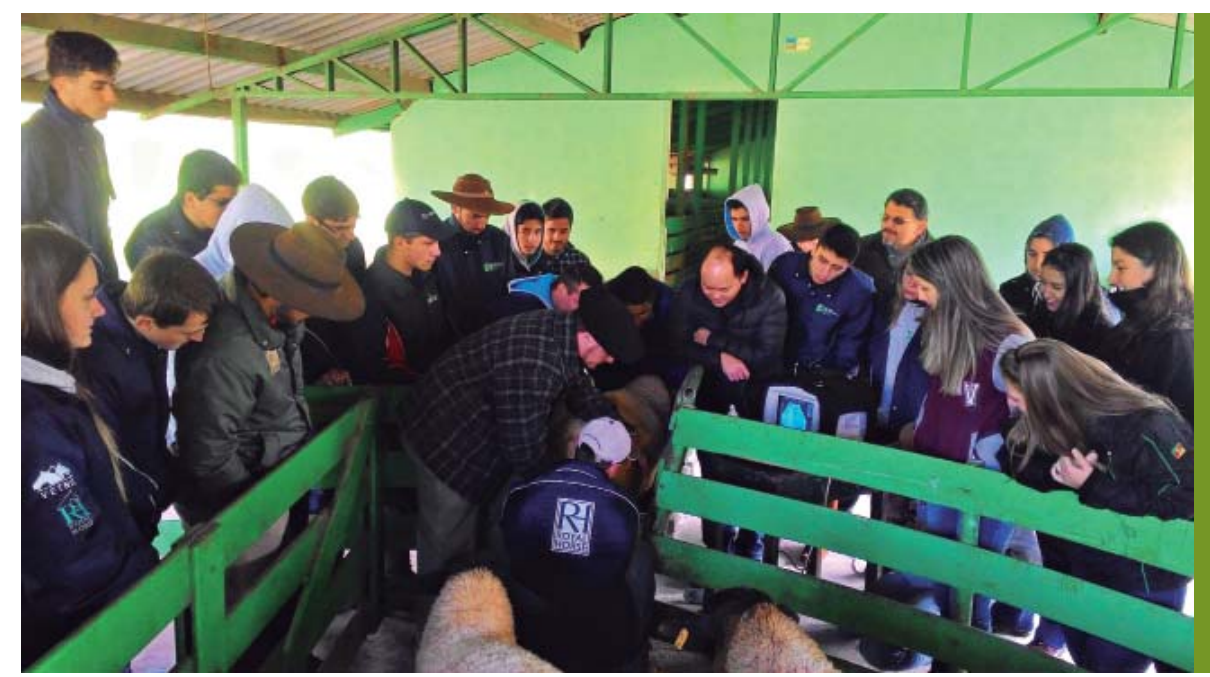

Figura 3: |a Manhã de Campo em Ovinocultura do IFRS Campus Sertão.

Fonte: Guilherme Afonso Müller Rodrigues.

Com as atividades desenvolvidas ao longo do projeto, efetuou-se um diagnóstico da situação em que se encontra a ovinocultura na região de abrangência do IFRS - Câmpus Sertão e, por meio das técnicas repassadas e das conversas durante as visitas, as UPAs participantes obtiveram avanços sanitários, nutricionais e reprodutivos em seus rebanhos.

Devido ao sucesso do projeto, estuda-se a elaboração do planejamento para continuidade desse trabalho, com o propósito de oportunizar o atendimento e parceria com produtores, que nos anos anteriores, não foram atendidos por incompatibilidade de agendas ou escassez de vagas e recursos. Desse modo, pretende-se corroborar significativamente para a estruturação e fortalecimento da ovinocultura regional, bem como proporcionar maior desenvolvimento social e econômico, abrindo portas para uma nova modalidade de produção na região. Ainda, as atividades desenvolvidas oportunizaram aos acadêmicos relacionar os conhecimentos técnicos com os de consultoria rural, expondo a importância de ambos estarem ligados, visto que, alguns autores, apontam a necessidade de os agricultores, pecuaristas e profissionais técnicos encararem a gestão como parte fundamental para controlar as unidades de produção agropecuárias (BREITENBACH, 2014, 141-159). 0 desenvolvimento deste projeto agregou também profissionalismo, responsabilidade, comprometimento e capacidade comunicativa aos envolvidos, colaborando para a capacitação dos futuros profissionais ingressantes no mercado de trabalho, através do contato com realidades técnicas mais próximas das quais poderão ser encontradas futuramente.

\section{Referências}

BREITENBACH, Raquel. Gestão rural no contexto do agronegócio: desafios e limitações. Desafio Online, v. 2, n. 2, p. 141-159, 2014.

CELESTINO, João Garibaldi Almeida Viana Vicente; SILVEIRA, Pires. Análise econômica da ovinocultura: estudo de caso na Metade Sul do Rio Grande do Sul, Brasil. Ciência Rural, v. 39, n. 4, p. 1187-1192, 2009.

TAMIOZZO, Ângelo Otávio Calegaro et al. Extensão e integração: ampliando o conhecimento e a troca de informações entre produtores e técnicos envolvidos com a ovinocultura do norte gaúcho. Revista Viver IFRS, v. 4, n. 4, p. 68-71, 2016. 